\title{
AN EXPERIMENTAL EXAMINATION OF PECK LOCATION FOLLOWING MONOCULAR DISC- RIMINATION TRAINING IN THE PIGEON
}

\author{
Shigeru Watanabe
}

\section{Keio University}

In operant conditioning, an operant is defined as a class of responses (5), and the frequency of response and the time interval between the responses (IRT) are measured. The topography of response is also examined, but the research on this is limited.

In a study of the pecking response of the pigeon, the peck location can be measured by two different methods. The first method is by dividing a pecking key into several sectors which can be operated independantly. A microswitch attached to each sector counts the pecks on each one. This technique is convenient for a numerical treatment of a data, but the number of sectors which can be determined, i. e., the number of categories of peck location, is limited. The second method is by recording the peck impact on a carbon paper fastened to a pecking key. This technique was first suggested by Skinner (4). The peck location can be directly visualized on a carbon record, but a numerical treatment of a data cannot be gained.

Two factors which have some effect on the peck location were discussed by Beale and Corballis (1) and Jenkins and Sainsbury (3). The first is wether left or right eye is used in testing monocularly trained subjects and the other, the position of the stimulus displayed on a key. Beale and Corballis (1) divided a pecking key into left and right halves and found that pigeons monocularly trained on a mirror image discrimination emitted more responses on the half of the key facing the trained eye, and when they were tested with the untrained eye the side of the key on which more responses were emitted was shifted to the other half. Thus, the peck location is found to be 
controlled by which of the eyes is used in testing. They called this phenomenon the beak shift and attempted to explain the mirror image reversal effect with it. However, BEALE and Williams (2) reported that some pigeons showed the mirror image reversal effect without showing the beak shift. Thus, the beak shift is not crucial to the mirror image reversal effect.

JENKInS and SAINSBURY ( 3 ), employing the carbon record method, reported that the pigeon trained on a feature-positive discrimination (a key with a dot was $\mathrm{S}^{\mathrm{D}}$ and a blank key $\mathrm{S}^{\Delta}$ ) centered its pecks on the feature stimulus (the dot). Thus, the peck location is controlled by the position of timulus. They also used the first method and confirmed the concentration of pecks on the sector on which a feature stimulus was displayed.

In the present experiment, a translucent no-carbon paper which permits a projection of a stimulus on a pecking key was used. And the effect of the eye used in testing and that of the stimulus location were examined with monocularly trained pigeons.

\section{METHOD}

Subjects : Thirteen pigeons maintained at about 80 percent of their free feeding weights were used. Two of the subjects had been trained on a monocular mirror image discrimination between a line obliqued at $135^{\circ}$ and a line obliqued at $45^{\circ}$ (details of the procedure and results of this discrimination training were given in Watanabe $(6)$ ). Six subjects had been trained on a monocular interdimensional discrimination between a short line obliqued at $45^{\circ}$ on the upper left of a pecking key and a blank key, and other five sujects had been trained on a monocular intradimensional discrimination between a short line on the upper left of a key and a short vertical line (details of the procedure and results of this discrimination training were given in $\left.\mathrm{W}_{\mathrm{ATANABE}}(\mathbf{7})\right)$. The final schedule of these trainings were mult VI-EXT in every case.

Apparatus: The experimental chamber was a modified Skinner box with a single key. The diameter of the key was $30 \mathrm{~mm}$. In order to record the peck location, a tracing paper covered by a no-carbon paper was fastened to the key. Two different line stimuli could be projected on the illuminated key. One was a dark line $2 \mathrm{~mm}$ in width and $30 \mathrm{~mm}$ in length and the other $2 \mathrm{~mm}$ in width and 
$15 \mathrm{~mm}$ in length.

Procedure: Following each discrimination training described above, a peck location test was administered using each eye. During the test, every tenth response was reinforced by four second presentation of food magazine (FR 10) until the subjects emitted 100 responses. Only one stimulus was presented in one test and a blackout was not employed. Subjects trained on the mirror image discrimination (73001 and 72175) were subjected to six peck location tests. A test with $\mathrm{S}^{\mathrm{D}}$, a test with its upper half and a test with its lower half were carried out using the trained eye. Then, a test with the mirror image of $\mathrm{S}^{\mathrm{D}}$ (that is, $\mathrm{S}^{4}$ ), a test with its upper half and a test with its lower half were carried out

Table 1. Results of Peck Location
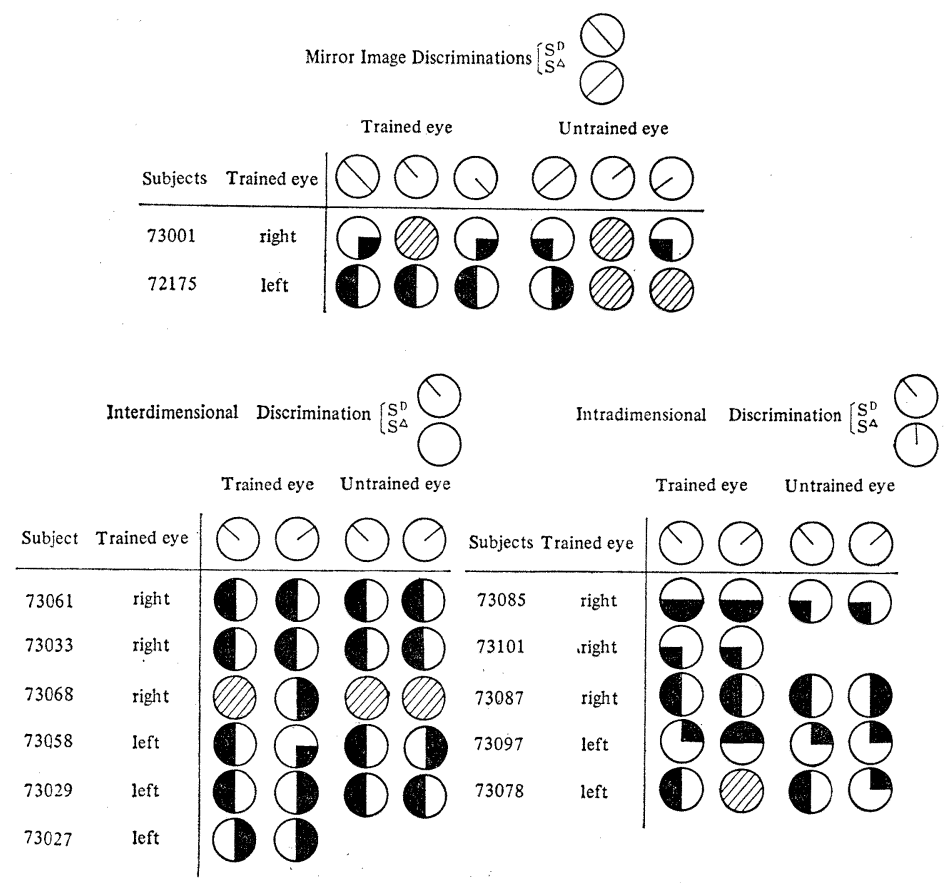

Table 1. Each circle illustrats schematic results of peck location tests. Dark portion of circles represents concentration of pecks and circles with obliqued stripes means that no clear concentration of pecks was obtained. Second column in each table (Trained eye) represents the eye used during the monocular trainining. 
using the untrained eye.

Other pigeons trained on the discrimination with short line stimulus were subjected to a peck location test with $\mathrm{S}^{\mathrm{D}}$ and another with its lateral mirror image. These two tests were first administered using the trained eye and then using the untrained eye.

\section{RESULTS}

Table 1 summarizes the results of the peck location tests. Examples of records of peck location after the mirror image discrimination training are illustrated in Fig. 1. Pigeon 72175, which was monocularly trained with its left eye, concentrated its responses on the left half of the key in all tests using the trained eye. However, it concentrated its responses on the right half of the key when tested with $\mathrm{S}^{\Delta}$ using the untrained eye. But a clear concentration of pecks was not obtained in the tests with the shortened line under the above eye condition. Pigeon 73001, trained with its right eye, pecked more of ten on the lower right quardent in the test with $\mathrm{S}^{\mathrm{D}}$ using the trained eye. When it used its untrained eye, it pecked more often on the lower left quardent in the

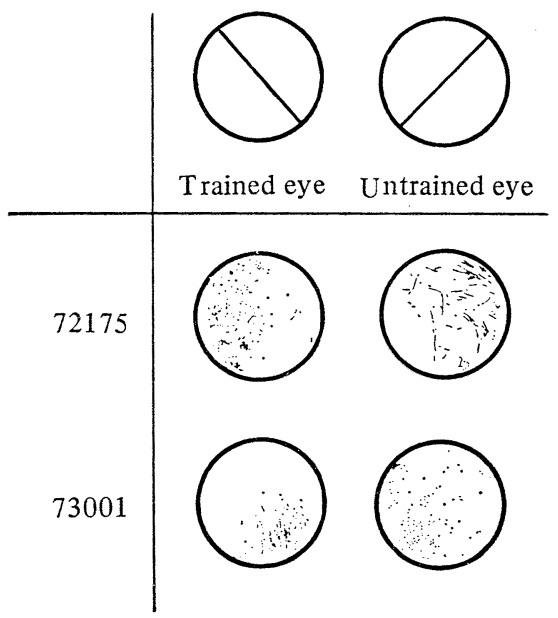

Fig. 1. Peck Location after Mirror Image Discrimination

Both subjects were monocularly trained on the mirror image discrimination in which $\mathrm{S}^{D}$ was $135^{\circ}$ line (left) and $\mathrm{S}^{4} 45^{\circ}$ line (right). 
test with $\mathrm{S}^{\Delta}$. Results of the tests with the shortened line were not clear.

Some examples of records of peck location after the interdimensional discrimination training are illustrated in Fig. 2. As summarized in Table 1 , four of the six subjects trained on this discrimination (73029, 73058, 73033 and 73061) emitted more responses on the left half of the key in

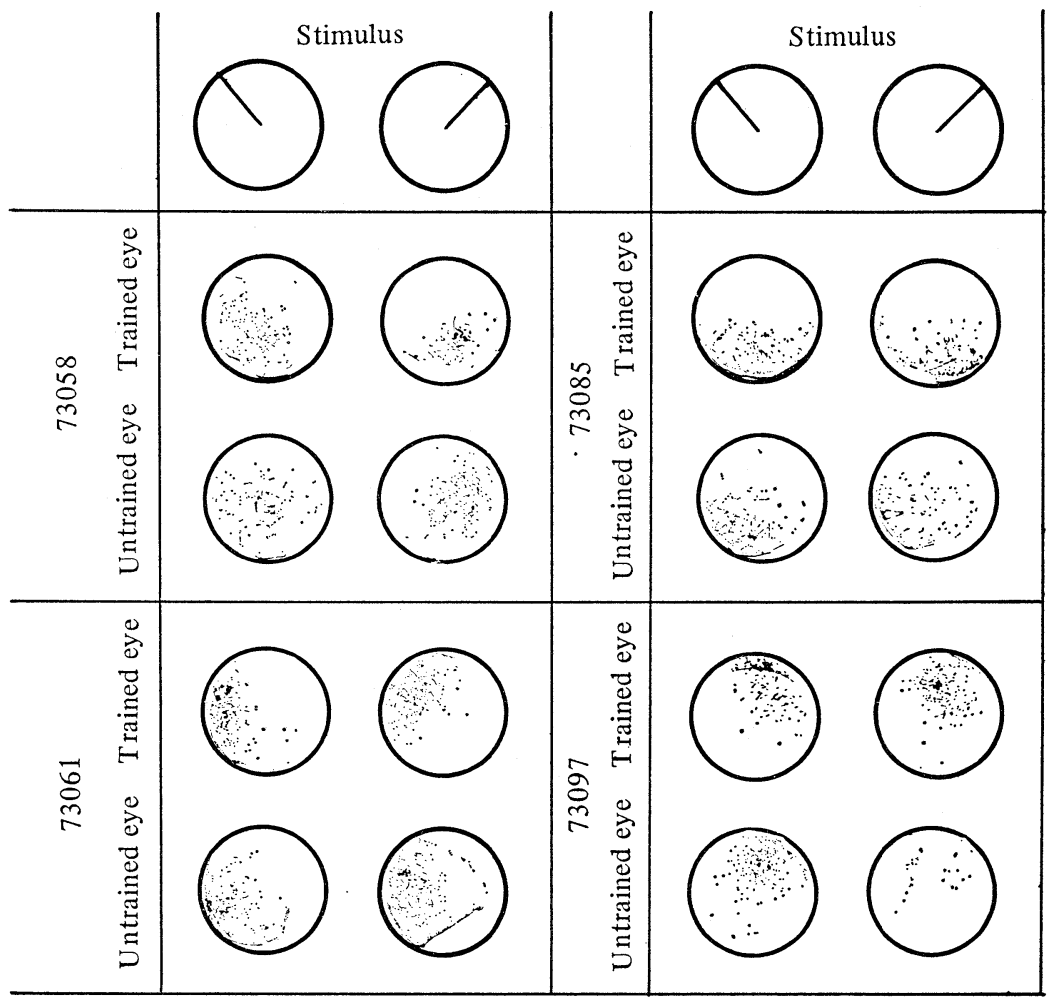

Fig. 2. Peck Location after Interdimensional or Intradimensional Discrimination Subjects 73058 and 73061 were monocularly trained on the interdimensional discrimination in which $\mathrm{S}^{\mathrm{D}}$ was the line at the upper left of the key and $\mathrm{S}^{4}$ the blank key. Subjects 73085 and 73097 were monocularly trained on the intradimensional discrimination in which $\mathrm{S}^{D}$ was the line at the upper left of the key and $\mathrm{S}^{4}$ was the vertical line. 73097 did not emit 100 pecks in the test with the mirror image of $\mathrm{S}^{\mathrm{D}}$ using the untrained eye. 
the test with $\mathrm{S}^{\mathrm{D}}$ when they used their trained eye. Pigeon 73027 concentrated its responses on the right half of the key, but pigeon 730 68 did not show a clear concentration under the above eye condition. In the test with the mirror image of $\mathrm{S}^{\mathrm{D}}$ using the trained eye, two subjects (73058 and 73029)shifted their peck location from left to right. But other subjects did not demonstrate such a shift under the above eye condition. When the subjects used their untrained eye, four of the five subjects (73061, 73058, 73029 and 73033) showed a concentration of pecks on the left half of the key in the test with the $S^{D}$. Thus, a shift of peck location through a transfer of the eye being used was not demonstrated. When they were tested with the mirror image of $\mathrm{S}^{\mathrm{D}}$ using the untrained eye, one pigeon (73058) concentrated its pecks on the right half of the key, that is, it shifted its peck location from left to right through a change of the stimulus. But other subjects did not show a similar shift of peck location.

Examples of the results of the subjects trained on the intradimensional discrimination are shown in Fig. 2. Results are varied as represented in Table 1. When the subjects used their trained eye, pigeon 73085 emitted more pecks on the lower half of the key, 73101 on the lower left quardent, 73087 on the left half and 73097 on the upper half or upper right quardent in both tests with $\mathrm{S}^{\mathrm{D}}$ and with its mirror image. Pigeon 73078. concentrated its responses on the left half in the test with $\mathrm{S}^{\mathrm{D}}$ but did not show such a tendency in the test with the mirror image of $\mathrm{S}^{\mathrm{D}}$ using the trained eye. Therefore, a shift of peck location through a change of the stimulus was not obtained. When they used their untrained eye, pigeon 73085 pecked more of ten on the lower left quardent, 73087 on the left half, 73097 on the upper right quardent and 73078 on the left half in the test with the $\mathrm{S}^{\mathrm{D}}$. A shift of peck location through a transfer of the eye was not demonstrated. Pigeon 73087 shifted its peck location from left to right when tested with the mirror image of the $\mathrm{S}^{\mathrm{D}}$ using the untrained eye. Pigeon 73078 also indicated some modification of peck location through a change of the stimulus when tested with its untrained eye. But pigeon 73085 did not show a change of peck location in any of the tests. Therefore, 
a shift of peck location through a change of stimulus was obtained sometimes but that through a transfer of the eye was not indicated.

\section{Discussion}

The results of the peck location tests of the subjects trained on the mirror image discrimination can be summarized as follows. The subjects concentrated their pecks on the half of the key facing the trained eye when tested with the trained eye, and when they were tested with the untrained eye they shifted their peck location to the other side. However, factors which determine the peck location cannot be specified in this case because both the eye used and the stimulus presented were concurrently changed in the test using the untrained eye.

After the interdimensional discrimination training, most of the subjects pecked more often on the half of the key on which $\mathrm{S}^{\mathrm{D}}$ was dispayed, and no subject indicated a shift of peck location through a transfer of the eye but that through a change in stimulus location was recorded sometimes. These results support the finding by JENKINS and SAINSBURY ( 3 ), because the interdimensional discrimination used in the present experiments is considered to be the feature positive discrimination described in their report. But the concentration of pecks was clearer in Jenkins and Sainsbury, so the dot stimulus used in their experiment seems to be more effective in concentrating responses than a line stimulus. According to the previous report ( 7 ), some of the subjects in the interdimensional discrimination training group showed a bimodal generalization gradient with peaks at $\mathrm{S}^{\mathrm{D}}$ and its lateral mirror image but some did not show a similar gradient. However, a clear relationship between the dimensional control and the peck location cannot be found.

Variation of peck location after the intradimensional discrimination training may be caused by $\mathrm{S}^{\Delta}$ along the same dimension to $\mathrm{S}^{\mathrm{D}}$. In other words, the intradimensional discrimination cannot be considered to be a feature-positive discrimination. But it must be pointed out that a shift of peck location through a change in stimulus location was obtained sometimes. The subjects trained on this discrimination showed 
the mirror image reversal effect ( 7 ). But the relationship between discriminative behavior and peck location cannot be clarified in this case.

In summary, following three points are suggested : 1) peck location is not completely determined by the location of stimulus but the location of $\mathrm{S}^{\mathrm{D}}$ during monocular training is important at least in the case of feature-positive discrimination, 2) shift of peck location through a change in stimulus location is obtained sometimes but not through a transfer of the eye and 3) a clear relation between the discriminative behavior and peck location is not recognized.

\section{REFERENCES}

1. Beale, I. L. and Corballis, M. C. Beak shift:An explanation for interocular mirror image reversal in pigeons. Nature, 1968, 220, 82-83.

2. Beale, I. L. and Williams, R. J. Experimental control of beak shift during tests for interocular transfer of a lateral mirror image discrimination. Psychon. Sci., 1971, 24, 7-8.

3. Jenkins, H.M. and Sainsbury, R.S. Discrimination learning with the distinctive feature on positive or negative trials. In Mostofsky, D. I. (Ed.) Attention: Contemporary theory and analysis. 1970, New York: Appleton Century.

4. Skinner, B.F. Stimulus generalization in an operant : A historical note. In Mostofsкy, D. I. (Ed.) Stimulus generalization. 1965, Stanford : Stanford Univ. Press.

5. Thompson, D. and Grabowski, J.G. Reinforcement Schedule and multioperant analysis. 1972, New York: Appleton Century.

6. Watanabe, S. Interocular transfer of stimulus control in pigeons. The Ann. Anim. Psychol., 1974, 24, 1-14.

7. Watanabe, S. Interocular transfer of generalization along line-tilt dimension in pigeons: A separation of three types of symmetric stimuli. The Jap. Psychol. Res., 1975, 17, 133-140. 